CIRJE-F-643

\title{
Has the Basel II Accord Encouraged Risk Management During the 2008-09 Financial Crisis?
}

\author{
Michael McAleer \\ Erasmus University Rotterdam \\ and Tinbergen Institute \\ and CIRJE, Faculty of Economics, University of Tokyo \\ Juan-Angel Jimenez-Martin \\ Complutense University of Madrid \\ Teodosio Pérez-Amaral \\ Complutense University of Madrid
}

August 2009

CIRJE Discussion Papers can be downloaded without charge from:

http://www.e.u-tokyo.ac.jp/cirje/research/03research02dp.html

Discussion Papers are a series of manuscripts in their draft form. They are not intended for circulation or distribution except as indicated by the author. For that reason Discussion Papers may not be reproduced or distributed without the written consent of the author. 


\title{
Has the Basel II Accord Encouraged Risk Management During the 2008-09 Financial Crisis?*
}

\author{
Michael McAleer \\ Econometric Institute \\ Erasmus School of Economics \\ Erasmus University Rotterdam \\ and \\ Tinbergen Institute \\ The Netherlands \\ and \\ Center for International Research on the Japanese Economy (CIRJE) \\ Faculty of Economics \\ University of Tokyo
}

\author{
Juan-Angel Jimenez-Martin \\ Department of Quantitative Economics \\ Complutense University of Madrid
}

Teodosio Pérez-Amaral

Department of Quantitative Economics

Complutense University of Madrid

August 2009

* The first author wishes to thank the Australian Research Council and National Science Council, Taiwan, for financial support. The second and third authors acknowledge the financial support of the Ministerio de Ciencia y Tecnología, Spain, and Comunidad de Madrid. 


\begin{abstract}
The Basel II Accord requires that banks and other Authorized Deposit-taking Institutions (ADIs) communicate their daily risk forecasts to the appropriate monetary authorities at the beginning of each trading day, using one or more risk models to measure Value-at-Risk (VaR). The risk estimates of these models are used to determine capital requirements and associated capital costs of ADIs, depending in part on the number of previous violations, whereby realised losses exceed the estimated VaR. In this paper we define risk management in terms of choosing sensibly from a variety of risk models, discuss the selection of optimal risk models, consider combining alternative risk models, discuss the choice between a conservative and aggressive risk management strategy, and evaluate the effects of the Basel II Accord on risk management. We also examine how risk management strategies performed during the 2008-09 financial crisis, evaluate how the financial crisis affected risk management practices, forecasting $\mathrm{VaR}$ and daily capital charges, and discuss alternative policy recommendations, especially in light of the financial crisis. These issues are illustrated using Standard and Poor's 500 Index, with an emphasis on how risk management practices were monitored and encouraged by the Basel II Accord regulations during the financial crisis.
\end{abstract}

Key words and phrases: Value-at-Risk ( $\mathrm{VaR})$, daily capital charges, exogenous and endogenous violations, violation penalties, optimizing strategy, risk forecasts, aggressive or conservative risk management strategies, Basel II Accord, financial crisis.

JEL Classifications: G32, G11, G17, C53, C22. 


\section{Introduction}

The financial crisis of 2008-09 has left an indelible mark on economic and financial structures worldwide, and left an entire generation of investors wondering how things could have become so severe. There have been many questions asked about whether appropriate regulations were in place, especially in the USA, to permit the appropriate monitoring and encouragement of (possibly excessive) risk taking.

The Basel II Accord was designed to monitor and encourage sensible risk taking using appropriate models of risk to calculate Value-at-Risk (VaR) and subsequent daily capital charges. VaR is defined as an estimate of the probability and size of the potential loss to be expected over a given period, and is now a standard tool in risk management. It has become especially important following the 1995 amendment to the Basel Accord, whereby banks and other Authorized Deposit-taking Institutions (ADIs) were permitted (and encouraged) to use internal models to forecast daily VaR (see Jorion (2000) for a detailed discussion). The last decade has witnessed a growing academic and professional literature comparing alternative modelling approaches to determine how to measure VaR, especially for large portfolios of financial assets.

The amendment to the initial Basel Accord was designed to encourage and reward institutions with superior risk management systems. A back-testing procedure, whereby actual returns are compared with the corresponding VaR forecasts, was introduced to assess the quality of the internal models used by ADIs. In cases where internal models lead to a greater number of violations than could reasonably be expected, given the confidence level, the ADI is required to hold a higher level of capital (see Table 1 for the penalties imposed under the Basel II Accord). Penalties imposed on ADIs affect profitability directly through higher capital charges, and indirectly through the imposition of a more stringent external model to forecast VaR. This is one reason why financial managers may prefer risk management strategies that are passive and conservative rather than active and aggressive.

Excessive conservatism can have a negative impact on the profitability of ADIs as higher capital charges are subsequently required. Therefore, ADIs should perhaps consider a strategy that allows an endogenous decision as to how many times ADIs 
should violate in any financial year (for further details, see McAleer and da Veiga (2008a, 2008b), McAleer (2008), Caporin and McAleer (2009b) and McAleer et al. (2009)). This paper suggests alternative aggressive and conservative risk management strategies that can be compared with the use of one or more models of risk throughout the estimation and forecasting periods.

This paper defines risk management in terms of choosing sensibly from a variety of risk models, discusses the selection of optimal risk models, considers combining alternative risk models, discusses the choice between conservative and aggressive risk management strategies, evaluates the effects of the Basel II Accord on risk management, examines how risk management strategies performed during the 2008-09 financial crisis, evaluates how the financial crisis affected risk management practices, forecasts $\mathrm{VaR}$ and daily capital charges, and discusses alternative policy recommendations, especially in light of the financial crisis.

These issues are illustrated using Standard and Poor's 500 Index, with an emphasis on how risk management practices were monitored and encouraged by the Basel II Accord regulations during the financial crisis.

The remainder of the paper is as follows. In Section 2 we present the main ideas of the Basel II Accord Amendment as it relates to forecasting VaR and daily capital charges. Section 3 reviews some of the most well known models of volatility that are used to forecast $\mathrm{VaR}$ and calculate daily capital charges, and presents aggressive and conservative bounds on risk management strategies. In Section 4 the data used for estimation and forecasting are presented. Section 5 analyses the forecast values of VaR and daily capital charges before and during the 2008-08 financial crisis, and Section 6 summarizes the main conclusions.

\section{2. $\quad$ Forecasting Value-at-Risk and Daily Capital Charges}

The Basel II Accord stipulates that daily capital charges (DCC) must be set at the higher of the previous day's VaR or the average VaR over the last 60 business days, multiplied by a factor $(3+k)$ for a violation penalty, wherein a violation involves the actual negative returns exceeding the VaR forecast negative returns for a given day: 


$$
D C C_{t}=\sup \left\{-(3+k) \overline{\mathrm{VaR}}_{60}, \quad-\mathrm{VaR}_{t-1}\right\}
$$

where

$D C C=$ daily capital charges, which is the higher of $-(3+k) \overline{\mathrm{VaR}}_{60}$ and $-\mathrm{VaR}_{t-1}$,

$V A R_{t}=$ Value-at-Risk for day $t$,

$V A R_{t}=\hat{Y}_{t}-z_{t} \cdot \hat{\sigma}_{t}$

$\overline{\mathrm{VaR}}_{60}=$ mean $\mathrm{VaR}$ over the previous 60 working days,

$\hat{Y}_{t}=$ estimated return at time $\mathrm{t}$,

$z_{t}=1 \%$ critical value of the distribution of returns at time $t$,

$\hat{\sigma}_{t}=$ estimated risk (or square root of volatility) at time $\mathrm{t}$,

$0 \leq k \leq 1$ is the Basel II violation penalty (see Table 1 ).

[Table 1 goes here]

The multiplication factor (or penalty), $k$, depends on the central authority's assessment of the ADI's risk management practices and the results of a simple back test. It is determined by the number of times actual losses exceed a particular day's VaR forecast (Basel Committee on Banking Supervision (1996)). The minimum multiplication factor of 3 is intended to compensate for various errors that can arise in model implementation, such as simplifying assumptions, analytical approximations, small sample biases and numerical errors that tend to reduce the true risk coverage of the model (see Stahl (1997)). Increases in the multiplication factor are designed to increase the confidence level that is implied by the observed number of violations to the 99 per cent confidence level, as required by the regulators (for a detailed discussion of $\mathrm{VaR}$, as well as exogenous and endogenous violations, see McAleer (2008), Jiménez-Martin et al. (2009), and McAleer et al. (2009)). 
In calculating the number of violations, ADIs are required to compare the forecasts of $\mathrm{VaR}$ with realised profit and loss figures for the previous 250 trading days. In 1995, the 1988 Basel Accord (Basel Committee on Banking Supervision (1988) was amended to allow ADIs to use internal models to determine their VaR thresholds (Basel Committee on Banking Supervision (1995)). However, ADIs that proposed using internal models are required to demonstrate that their models are sound. Movement from the green zone to the red zone arises through an excessive number of violations. Although this will lead to a higher value of $k$, and hence a higher penalty, a violation will also tend to be associated with lower daily capital charges.

Value-at-Risk refers to the lower bound of a confidence interval for a (conditional) mean, that is, a "worst case scenario on a typical day". If interest lies in modelling the random variable, $Y_{t}$, it could be decomposed as follows:

$$
Y_{t}=E\left(Y_{t} \mid F_{t-1}\right)+\varepsilon_{t}
$$

This decomposition states that $Y_{t}$ comprises a predictable component, $E\left(Y_{t} \mid F_{t-1}\right)$, which is the conditional mean, and a random component, $\varepsilon_{t}$. The variability of $Y_{t}$, and hence its distribution, is determined by the variability of $\varepsilon_{t}$. If it is assumed that $\varepsilon_{t}$ follows a distribution such that:

$$
\varepsilon_{t} \sim D\left(\mu_{t}, \sigma_{t}^{2}\right)
$$

where $\mu_{t}$ and $\sigma_{t}$ are the unconditional mean and standard deviation of $\varepsilon_{t}$, respectively, these can be estimated using a variety of parametric, semi-parametric or non-parametric methods. The VaR threshold for $Y_{t}$ can be calculated as:

$$
\operatorname{VaR}_{t}=E\left(Y_{t} \mid F_{t-1}\right)-\alpha \sigma_{t},
$$

where $\alpha$ is the critical value from the distribution of $\varepsilon_{t}$ to obtain the appropriate confidence level. It is possible for $\sigma_{t}$ to be replaced by alternative estimates of the conditional variance in order to obtain an appropriate $\mathrm{VaR}$ (for useful reviews of 
theoretical results for conditional volatility models, see Li et al. (2002) and McAleer (2005), who discusses a variety of univariate and multivariate, conditional, stochastic and realized. volatility models).

Some recent empirical studies (see, for example, Berkowitz and O'Brien (2001) and Gizycki and Hereford (1998)) have indicated that some financial institutions overestimate their market risks in disclosures to the appropriate regulatory authorities, which can imply a costly restriction to the banks trading activity. ADIs may prefer to report high $\mathrm{VaR}$ numbers to avoid the possibility of regulatory intrusion. This conservative risk reporting suggests that efficiency gains may be feasible. In particular, as ADIs have effective tools for the measurement of market risk, while satisfying the qualitative requirements, ADIs could conceivably reduce daily capital charges by implementing a context-dependent market risk disclosure policy. For a discussion of alternative approaches to optimize VaR and daily capital charges, see McAleer (2008) and McAleer et al. (2009).

The next section describes several volatility models that are widely used to forecast the 1-day ahead conditional variances and VaR thresholds.

\section{Models for Forecasting VaR}

As discussed previously, ADIs can use internal models to determine their VaR thresholds. There are alternative time series models for estimating conditional volatility. In what follows, we present several conditional volatility models to evaluate strategic market risk disclosure, namely GARCH, GJR and EGARCH, with both normal and $t$ distribution errors, where the degrees of freedom are estimated. For an extensive discussion of the theoretical properties of several of these models, see Ling and McAleer (2002a, 2002b, 2003a) and Caporin and McAleer (2009b). As an alternative to estimating the parameters, we also consider the exponential weighted moving average (EWMA) method by Riskmetrics ${ }^{T M}$ (1996) that calibrates the unknown parameters. Apart from EWMA, the models are presented in increasing order of complexity. 


\subsection{GARCH}

For a wide range of financial data series, time-varying conditional variances can be explained empirically through the autoregressive conditional heteroskedasticity (ARCH) model, which was proposed by Engle (1982). When the time-varying conditional variance has both autoregressive and moving average components, this leads to the generalized $\operatorname{ARCH}(p, q)$, or $\operatorname{GARCH}(p, q)$, model of Bollerslev (1986). It is very common to impose the widely estimated $\operatorname{GARCH}(1,1)$ specification in advance.

Consider the stationary $\mathrm{AR}(1)-\mathrm{GARCH}(1,1)$ model for daily returns, $y_{t}$ :

$$
y_{t}=\varphi_{1}+\varphi_{2} y_{t-1}+\varepsilon_{t}, \quad\left|\varphi_{2}\right|<1
$$

for $t=1, \ldots, n$, where the shocks to returns are given by:

$$
\begin{aligned}
& \varepsilon_{t}=\eta_{t} \sqrt{h_{t}}, \quad \eta_{t} \sim \operatorname{iid}(0,1) \\
& h_{t}=\omega+\alpha \varepsilon_{t-1}^{2}+\beta h_{t-1},
\end{aligned}
$$

and $\omega>0, \alpha \geq 0, \beta \geq 0$ are sufficient conditions to ensure that the conditional variance $h_{t}>0$. The stationary AR(1)-GARCH(1,1) model can be modified to incorporate a nonstationary $\operatorname{ARMA}(\mathrm{p}, \mathrm{q})$ conditional mean and a stationary $\operatorname{GARCH}(\mathrm{r}, \mathrm{s})$ conditional variance, as in Ling and McAleer (2003b).

\subsection{GJR}

In the symmetric GARCH model, the effects of positive shocks (or upward movements in daily returns) on the conditional variance, $h_{t}$, are assumed to be the same as the negative shocks (or downward movements in daily returns). In order to accommodate asymmetric behaviour, Glosten, Jagannathan and Runkle (1992) proposed a model (hereafter GJR), for which GJR(1,1) is defined as follows:

$$
h_{t}=\omega+\left(\alpha+\gamma I\left(\eta_{t-1}\right)\right) \varepsilon_{t-1}^{2}+\beta h_{t-1}
$$


where $\omega>0, \alpha \geq 0, \alpha+\gamma \geq 0, \beta \geq 0$ are sufficient conditions for $h_{t}>0$, and $I\left(\eta_{t}\right)$ is an indicator variable defined by:

$$
I\left(\eta_{t}\right)= \begin{cases}1, & \varepsilon_{t}<0 \\ 0, & \varepsilon_{t} \geq 0\end{cases}
$$

as $\eta_{t}$ has the same sign as $\varepsilon_{t}$. The indicator variable differentiates between positive and negative shocks, so that asymmetric effects in the data are captured by the coefficient $\gamma$. For financial data, it is expected that $\gamma \geq 0$ because negative shocks have a greater impact on risk than do positive shocks of similar magnitude. The asymmetric effect, $\gamma$, measures the contribution of shocks to both short run persistence, $\alpha+\gamma / 2$, and to long run persistence, $\alpha+\beta+\gamma / 2$. Although GJR permits asymmetric effects of positive and negative shocks of equal magnitude on conditional volatility, the special case of leverage, whereby negative shocks increase volatility while positive shocks decrease volatility (see Black (1976) for an argument using the debt/equity ratio), cannot be accommodated.

\subsection{EGARCH}

An alternative model to capture asymmetric behaviour in the conditional variance is the Exponential GARCH, or EGARCH(1,1), model of Nelson (1991), namely:

$$
\log h_{t}=\omega+\alpha\left|\frac{\varepsilon_{t-1}}{h_{t-1}}\right|+\gamma \frac{\varepsilon_{t-1}}{h_{t-1}}+\beta \log h_{t-1}, \quad|\beta|<1
$$

where the parameters $\alpha, \beta$ and $\gamma$ have different interpretations from those in the $\operatorname{GARCH}(1,1)$ and $\operatorname{GJR}(1,1)$ models.

EGARCH captures asymmetries differently from GJR. The parameters $\alpha$ and $\gamma$ in $\operatorname{EGARCH}(1,1)$ represent the magnitude (or size) and sign effects of the standardized residuals, respectively, on the conditional variance, whereas $\alpha$ and $\alpha+\gamma$ represent the effects of positive and negative shocks, respectively, on the conditional variance in 
GJR(1,1). Unlike GJR, EGARCH can accommodate leverage, depending on restrictions imposed on the size and sign parameters.

As noted in McAleer et al. (2007), there are some important differences between EGARCH and the previous two models, as follows: (i) EGARCH is a model of the logarithm of the conditional variance, which implies that no restrictions on the parameters are required to ensure $h_{t}>0$; (ii) moment conditions are required for the GARCH and GJR models as they are dependent on lagged unconditional shocks, whereas EGARCH does not require moment conditions to be established as it depends on lagged conditional shocks (or standardized residuals); (iii) Shephard (1996) observed that $|\beta|<1$ is likely to be a sufficient condition for consistency of QMLE for $\operatorname{EGARCH}(1,1)$; (iv) as the standardized residuals appear in equation (7), $|\beta|<1$ would seem to be a sufficient condition for the existence of moments; and (v) in addition to being a sufficient condition for consistency, $|\beta|<1$ is also likely to be sufficient for asymptotic normality of the QMLE of $\operatorname{EGARCH}(1,1)$.

\subsection{Exponentially Weighted Moving Average (EWMA)}

The three conditional volatility models given above are estimated under the following distributional assumptions on the conditional shocks: (1) normal, and (2) t, with estimated degrees of freedom. As an alternative to estimating the parameters of the appropriate conditional volatility models, Riskmetrics ${ }^{T M}$ (1996) developed a model which estimates the conditional variances and covariances based on the exponentially weighted moving average (EWMA) method, which is, in effect, a restricted version of the $\operatorname{ARCH}(\infty)$ model. This approach forecasts the conditional variance at time $t$ as a linear combination of the lagged conditional variance and the squared unconditional shock at time $t-1$. The EWMA model calibrates the conditional variance as:

$$
h_{t}=\lambda h_{t-1}+(1-\lambda) \varepsilon_{t-1}^{2}
$$

where $\lambda$ is a decay parameter. Riskmetrics ${ }^{\mathrm{TM}}$ (1996) suggests that $\lambda$ should be set at 0.94 for purposes of analysing daily data. As no parameters are estimated, there is no 
need to establish any moment or log-moment conditions for purposes of demonstrating the statistical properties of the estimators.

\section{Data}

The data used for estimation and forecasting are the closing daily prices for Standard and Poor's Composite 500 Index (S\&P500), which were obtained from the Ecowin Financial Database for the period 3 January 2000 to 12 February 2009.

If $P_{t}$ denotes the market price, the returns at time $t\left(R_{t}\right)$ are defined as:

$$
R_{t}=\log \left(P_{t} / P_{t-1}\right)
$$

\section{[Insert Figure 1 here]}

Figure 1 shows the S\&P500 returns, for which the descriptive statistics are given in Table 2. The extremely high positive and negative returns are evident from September 2008 onward, and have continued well into 2009. The mean is close to zero, and the range is between $-11 \%$ and $-9.5 \%$. The Jarque-Bera Lagrange multiplier test for normality rejects the null hypothesis of normally distributed returns. As the series displays high kurtosis, this would seem to indicate the existence of extreme observations, as can be seen in the histogram, which is not surprising for financial returns data.

\section{[Insert Table 2 here]}

Several measures of volatility are available in the literature. In order to gain some intuition, we adopt the measure proposed in Franses and van Dijk (1999), where the true volatility of returns is defined as:

$$
V_{t}=\left(R_{t}-E\left(R_{t} \mid F_{t-1}\right)\right)^{2}
$$

where $F_{t-1}$ is the information set at time $t-1$. 
Figure 2 shows the S\&P500 volatility, as defined in equation (11). The series exhibit clustering that needs to be captured by an appropriate time series model. The volatility of the series appears to be high during the early 2000 s, followed by a quiet period from 2003 to the beginning of 2007. Volatility increases dramatically after August 2008, due in large part to the worsening global credit environment. This increase in volatility is even higher in October 2008. In less than 4 weeks in October 2008, the S\&P500 index plummeted by $27.1 \%$. In less than 3 weeks in November 2008, starting the morning after the US elections, the S\&P500 index plunged a further 25.2\%. Overall, from late August 2008, US stocks fell by an almost unbelievable $42.2 \%$ to reach a low on 20 November 2008.

An examination of daily movements in the S\&P500 index back to 2000 suggests that large changes by historical standards are 4\% in either direction. From January 2000 to March 2008, there was a $0.4 \%$ chance of observing an increase of $4 \%$ or more in one day, and a $0.2 \%$ chance of seeing a reduction of $4 \%$ or more in one day. Therefore, $99.4 \%$ of movements in the S\&P500 index during this period had daily swings of less than 4\%. Prior to September 2008, the S\&P500 index had only 24 days with massive 4\% gains, but since September 2008, there have been 12 more such days. On the downside, before the current stock market meltdown, the S\&P500 index had only 18 days with huge $4 \%$ or more losses, whereas during the recent panic, there were a further 15 such days.

This comparison is between more than 58 years and just six months. During this short time span of financial panic, the $4 \%$ or more gain days increased by $72 \%$, while the number of $4 \%$ or more loss days increased by $106 \%$. Such movements in the S\&P500 index are unprecedented.

Alternative models of volatility can be compared on the basis of statistical significance, goodness of fit, forecasting VaR, calculation of daily capital charges, and optimality on a daily or temporally aggregated basis. As the focus of forecasting VaR is to calculate daily capital charges, subject to appropriate penalties, the most severe of which is temporary or permanent suspension from investment activities, the goodness of fit criterion used is the calculation of daily and mean capital charges, both before and after the 2008-09 financial crisis. 


\section{Forecasting VaR and Calculating Daily Capital Charges}

In this section, the forecast values of $\mathrm{VaR}$ and daily capital charges are analysed before and during the 2008-09 financial crisis. We consider alternative risk management strategies and propose some policy recommendations.

In Figure 3, VaR forecasts are compared with S\&P500 returns, where the vertical axis represents returns, and the horizontal axis represents the days from 2 January 2008 to 12 February 2009. The S\&P500 returns are given as the upper blue line that fluctuates around zero.

ADIs need not restrict themselves to using only one of the available risk models. In this paper we propose a risk management strategy that consists in choosing from among different combinations of alternative risk models to forecast VaR. We first discuss a combination of models that can be characterized as an aggressive strategy and another that can be regarded as a conservative strategy, as given in Figure 3.

The upper red line represents the infinum of the VaR calculated for the individual models of volatility, which reflects an aggressive risk management strategy, whereas the lower green line represents the supremum of the VaR calculated for the individual models of volatility, which reflects a conservative risk management strategy. These two lines correspond to a combination of alternative risk models.

[Insert Figure 3 here]

As can be seen in Figure 3, VaR forecasts obtained from the different models of volatility have fluctuated, as expected, during the first few months of 2008. It has been relatively low, at below 5\%, and relatively stable between April and August 2008. Around September 2008, VaR started increasing until it peaked in October 2008, between $10 \%$ and $15 \%$, depending on the model of volatility considered. This is essentially a four-fold increase in $\mathrm{VaR}$ in a matter of one and a half months. In the last two months of 2008 , VaR decreased to values between $5 \%$ and $8 \%$, which is still twice as large as it had been just a few months earlier. Therefore, volatility has increased substantially during the financial crisis, and has remained relatively high after the crisis. 
Figure 4 includes daily capital charges based on VaR forecasts and the mean VAR for the previous 60 days, which are the two lower smooth lines. The red line corresponds to the aggressive risk management strategy based on the infinum of the daily capital charges of the alternative models of volatility, and the green line corresponds to the conservative risk management strategy based on the supremum of the daily capital charges of the alternative models of volatility.

Before the financial crisis, there is a substantial difference between the two lines corresponding to the aggressive and conservative risk management strategies. However at the onset of the crisis, the two lines virtually coincide, which suggests that the moving average term in the Basel II formula, which dominates the calculation of daily capital charges, is excessive. This suggests that the use of a shorter moving average in the Basel II formula for calculating the DCC may lead to a closer vertical alignment between the troughs of the VaR and DCC lines, thereby leading to a closer correspondence between high values of $\mathrm{VaR}$ and high values of $\mathrm{DCC}$, as may be desirable.

After the crisis had begun, there is a substantial difference between the two strategies, arising from divergence across the alternative models of volatility, and hence between the aggressive and conservative risk management strategies.

[Insert Figure 4 here]

It can be observed from Figure 4 that daily capital charges always exceed VaR (in absolute terms). Moreover, immediately after the financial crisis had started, a significant amount of capital was set aside to cover likely financial losses. This is a positive feature of the Basel II Accord, since it can have the effect of shielding ADIs from possible significant financial losses.

The Basel II Accord would seem to have succeeded in covering the losses of ADIs before, during and after the financial crisis. Therefore, it is likely to be useful when extended to countries to which it does not currently apply. 
[Insert Figure 5 here]

Figure 5 shows the accumulated number of violations for each model of volatility over the period of 260 days considered (2 January 2008 to 12 February 2009). Table 3 gives the percentage of days for which daily capital charges are minimized, the mean daily capital charges, and the number of violations for the alternative models of volatility. The upper red line in Figure 5 corresponds to the aggressive risk management strategy, which yields 16 violations, thereby exceeding the recommended limit of 10 in 250 working days. The lower green line corresponds to the conservative risk management strategy, which gives only 3 violations. Although this small number of violations is well within the Basel II limits, it may, in fact, be too few as it is likely to lead to considerably higher daily capital charges.

It may be useful to consider other strategies that lie somewhat in the middle of the previous two, such as the median or the average value of the $\mathrm{VaR}$ forecasts for a given day. Another possibility could be the DYLES strategy, developed in McAleer et al. (2009), which seems to work well in practice.

It is also worth noting from Table 3 and Figure 6, which gives the duration of the minimum daily capital charges for the alternative models of volatility, that four models of risk, including the conservative risk management strategy, do not minimize daily capital charges for even one day. On the other hand, the aggressive risk management strategy minimizes the mean daily capital charge over the year relative to its competitors, and also has the highest frequency of minimizing daily capital charges. The EGARCH model with $t$ distribution errors also minimizes daily capital charges frequently, and has a low mean daily capital charge. However, it is interesting that the EGARCH model with normal errors has a mean daily capital charge that is almost as low as that of the aggressive risk management strategy, even though it rarely minimizes daily capital charges.

[Insert Figure 6 here]

In terms of choosing the appropriate risk model for minimizing DCC, the simulations results reported here would suggest the following: 
(1) Before the financial crisis, the best models for minimizing daily capital charges are GARCH and GJR.

(2) During the financial crisis, the best model is Riskmetrics.

(3) After the financial crisis, the best model is TEGARCH.

The financial crisis has affected risk management strategies by changing the optimal model for minimizing daily capital charges.

\section{Conclusion}

Under the Basel II Accord, ADIs have to communicate their risk estimates to the monetary authorities, and use a variety of $\mathrm{VaR}$ models to estimate risks. ADIs are subject to a back-test that compares the daily VaR to the subsequent realized returns, and ADIs that fail the back-test can be subject to the imposition of standard models that can lead to higher daily capital costs. Additionally, the Basel II Accord stipulates that the daily capital charge that the bank must carry as protection against market risk must be set at the higher of the previous day's VaR or the average VaR over the last 60 business days, multiplied by a factor $3+k$. An ADI's objective is to maximize profits, so they wish to minimize their capital charges while restricting the number of violations in a given year below the maximum of 10 allowed by the Basel II Accord.

In this paper we defined risk management in terms of choosing sensibly from a variety of conditional volatility (or risk) models, discussed the selection of optimal risk models, considered combining alternative risk models, choosing between a conservative and aggressive risk management strategy and evaluating the effects of the Basel II Accord on risk management. We also examined how risk management strategies performed during the 2008-09 financial crisis, evaluated how the financial crisis affected risk management practices, forecasted $\mathrm{VaR}$ and daily capital charges, and discussed alternative policy recommendations, especially in light of the 2008-09 financial crisis. These issues were illustrated using Standard and Poor's 500 Index, with an emphasis on how risk management practices were monitored and encouraged by the Basel II Accord regulations during the financial crisis. 
Volatility has increased four-fold during the 2008-09 financial crisis, and remained relatively high after the crisis. This may be a reason why the financial crisis has changed the choice of risk management model for optimizing daily capital charges. Alternative risk models were found to be optimal before and during the financial crisis.

In this paper we proposed the idea of constructing risk management strategies that used combinations of several models for forecasting VaR. It was found that an aggressive risk management strategy yielded the lowest mean capital charges, and had the highest frequency of minimizing daily capital charges throughout the forecasting period, but which also tended to violate too often. Such excessive violations can have the effect of leading to unwanted publicity, and temporary or permanent suspension from trading as an ADI. On the other hand, a conservative risk management strategy would have far fewer violations, and a correspondingly higher mean daily capital charge.

The area between the bounds provided by the aggressive and conservative risk management strategies would seem to be a fertile area for future research.

A risk management strategy that used different combinations of alternative risk models for predicting $\mathrm{VaR}$ and minimizing daily capital charges was found to be optimal. A risk model that leads to the median forecast of $\mathrm{VaR}$ may also be a useful risk management strategy, as would be the DYLES strategy established in McAleer et al. (2009).

The Basel II Accord rules have been successful in covering the losses of ADIs before, during and after the 2008-09 financial crisis. Their application could be recommended for as yet unregulated markets and countries. Another recommendation would be to modify the Basel II Accord for calculating daily capital charges to shorten the moving average, to (say) 20 days, from the current 60 previous working days. This would allow a speedier adjustment of daily capital charges to changes in VaR, thereby avoiding the excessive lags observed in the simulations reported in the paper. 


\section{References}

Basel Committee on Banking Supervision, (1988), International Convergence of Capital Measurement and Capital Standards, BIS, Basel, Switzerland.

Basel Committee on Banking Supervision, (1995), An Internal Model-Based Approach to Market Risk Capital Requirements, BIS, Basel, Switzerland.

Basel Committee on Banking Supervision, (1996), Supervisory Framework for the Use of "Backtesting" in Conjunction with the Internal Model-Based Approach to Market Risk Capital Requirements, BIS, Basel, Switzerland.

Berkowitz, J. and J. O'Brien (2001), How accurate are value-at-risk models at commercial banks?, Discussion Paper, Federal Reserve Board.

Black, F. (1976), Studies of stock market volatility changes, in 1976 Proceedings of the American Statistical Association, Business and Economic Statistics Section, pp. 177-181.

Bollerslev, T. (1986), Generalised autoregressive conditional heteroscedasticity, Journal of Econometrics, 31, 307-327.

Caporin, M. and M. McAleer (2009a), Do we really need both BEKK and DCC? A tale of two covariance models (Available at SSRN: http://ssrn.com/abstract=1338190).

Caporin, M. and M. McAleer (2009b), The Ten Commandments for managing investments, to appear in Journal of Economic Surveys (Available at SSRN: http://ssrn.com/abstract=1342265).

Engle, R.F. (1982), Autoregressive conditional heteroscedasticity with estimates of the variance of United Kingdom inflation, Econometrica, 50, 987-1007.

Franses, P.H. and D. van Dijk (1999), Nonlinear Time Series Models in Empirical Finance, Cambridge, Cambridge University Press.

Gizycki, M. and N. Hereford (1998), Assessing the dispersion in banks' estimates of market risk: the results of a value-at-risk survey, Discussion Paper 1, Australian Prudential Regulation Authority.

Glosten, L., R. Jagannathan and D. Runkle (1992), On the relation between the expected value and volatility of nominal excess return on stocks, Journal of Finance, 46, 1779-1801.

Jimenez-Martin, J.-A., McAleer, M. and T. Peréz-Amaral (2009), The Ten Commandments for managing value-at-risk under the Basel II Accord, to appear 
in Journal of Economic Surveys (Available at SSRN: http://ssrn.com/abstract=1356803).

Jorion, P. (2000), Value at Risk: The New Benchmark for Managing Financial Risk, McGraw-Hill, New York.

Li, W.K., S. Ling and M. McAleer (2002), Recent theoretical results for time series models with GARCH errors, Journal of Economic Surveys, 16, 245-269. Reprinted in M. McAleer and L. Oxley (eds.), Contributions to Financial Econometrics: Theoretical and Practical Issues, Blackwell, Oxford, 2002, pp. 9-33. Ling, S. and M. McAleer (2002a), Stationarity and the existence of moments of a family of GARCH processes, Journal of Econometrics, 106, 109-117.

Ling, S. and M. McAleer (2002b), Necessary and sufficient moment conditions for the $\operatorname{GARCH}(\mathrm{r}, \mathrm{s})$ and asymmetric power $\operatorname{GARCH}(\mathrm{r}, \mathrm{s})$ models, Econometric Theory, $18,722-729$.

Ling, S. and M. McAleer, (2003a), Asymptotic theory for a vector ARMA-GARCH model, Econometric Theory, 19, 278-308.

Ling, S. and M. McAleer (2003b), On adaptive estimation in nonstationary ARMA models with GARCH errors, Annals of Statistics, 31, 642-674.

McAleer, M. (2005), Automated inference and learning in modeling financial volatility, Econometric Theory, 21, 232-261.

McAleer, M. (2008), The Ten Commandments for optimizing value-at-risk and daily capital charges, to appear in Journal of Economic Surveys (Available at SSRN: http://ssrn.com/abstract=1354686).

McAleer, M., F. Chan and D. Marinova (2007), An econometric analysis of asymmetric volatility: theory and application to patents, Journal of Econometrics, 139, 259284.

McAleer, M., J.-Á. Jiménez-Martin and T. Peréz-Amaral (2009), A decision rule to minimize daily capital charges in forecasting value-at-risk (Available at SSRN: http://ssrn.com/abstract=1349844).

McAleer, M. and B. da Veiga (2008a), Forecasting value-at-risk with a parsimonious portfolio spillover GARCH (PS-GARCH) model, Journal of Forecasting, 27, 1-19.

McAleer, M. and B. da Veiga (2008b), Single index and portfolio models for forecasting value-at-risk thresholds, Journal of Forecasting, 27, 217-235.

Nelson, D.B. (1991), Conditional heteroscedasticity in asset returns: a new approach, Econometrica, 59, 347-370. 
Riskmetrics $^{\mathrm{TM}}$ (1996), J.P. Morgan Technical Document, $4^{\text {th }}$ Edition, New York, J.P. Morgan.

Shephard, N. (1996), Statistical aspects of ARCH and stochastic volatility, in O.E. Barndorff-Nielsen, D.R. Cox and D.V. Hinkley (eds.), Statistical Models in Econometrics, Finance and Other Fields, Chapman \& Hall, London, pp. 1-67. Stahl, G. (1997), Three cheers, Risk, 10, 67-69. 
Table 1: Basel Accord Penalty Zones

\begin{tabular}{|l|c|c|}
\hline Zone & Number of Violations & $k$ \\
\hline Green & 0 to 4 & 0.00 \\
\hline Yellow & 5 & 0.40 \\
& 6 & 0.50 \\
& 8 & 0.65 \\
& 9 & 0.75 \\
& $10+$ & 0.85 \\
\hline Red & 1.00 \\
\hline $\begin{array}{l}\text { Note: The number of violations is given for 250 business days. } \\
\text { The penalty structure under the Basel II Accord is specified for } \\
\text { the number of violations and not their magnitude, either } \\
\text { individually or cumulatively. }\end{array}$ \\
\hline
\end{tabular}


Table 2. Descriptive Statistics for S\&P500 Returns

3 January 2000 - 12 February 2009

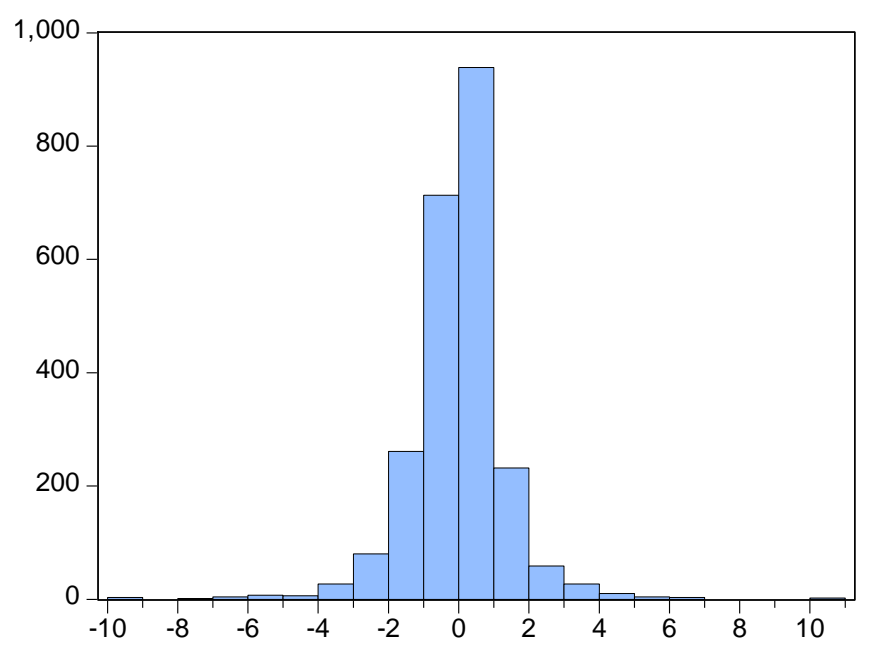

Series: S\&P 500 returns (\%) Sample 3/01/2000 12/02/2009

Observations 2378

Mean $\quad-0.023350$

Median $\quad 0.000177$

Maximum $\quad 10.95792$

Minimum $\quad-9.469733$

Std. Dev. $\quad 1.352380$

Skewness $\quad-0.158294$

Kurtosis $\quad 11.92801$

Jarque-Bera $\quad 7907.807$

Probability $\quad 0.000000$ 
Table 3. Percentage of Days Minimizing Daily Capital Charges, Mean Daily Capital Charges, and Number of Violations for Alternative Models of Volatility

\begin{tabular}{lccc}
\hline Model & $\begin{array}{c}\text { \% of Days } \\
\text { Minimizing Daily } \\
\text { Capital Charges }\end{array}$ & $\begin{array}{c}\text { Mean Daily } \\
\text { Capital Charges }\end{array}$ & $\begin{array}{c}\text { Number of } \\
\text { Violations }\end{array}$ \\
\hline Riskmetrics & $14.0 \%$ & 0.163 & 10 \\
GARCH & $0.0 \%$ & 0.161 & 13 \\
GJR & $10.0 \%$ & 0.157 & 7 \\
EGARCH & $1.70 \%$ & 0.146 & 13 \\
GARCH_t & $0.00 \%$ & 0.171 & 3 \\
GJR_t & $0.00 \%$ & 0.167 & 3 \\
EGARCH_t & $34.0 \%$ & 0.153 & 3 \\
Lower bound & $0.00 \%$ & 0.177 & 3 \\
Upper bound & $39.6 \%$ & 0.143 & 16 \\
\hline
\end{tabular}


Figure 1. Daily Returns on the S\&P500 Index,

3 January 2000 - 12 February 2009

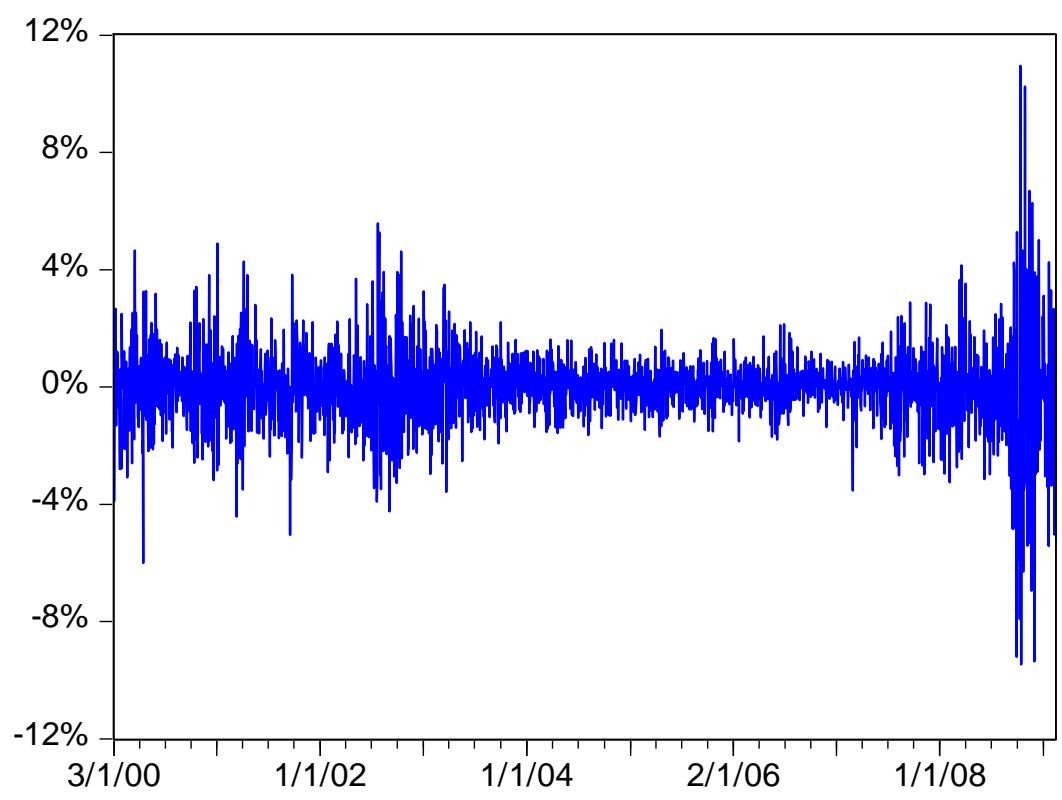


Figure 2. Daily Volatility in S\&P500 Returns

3 January 2000 - 12 February 2009

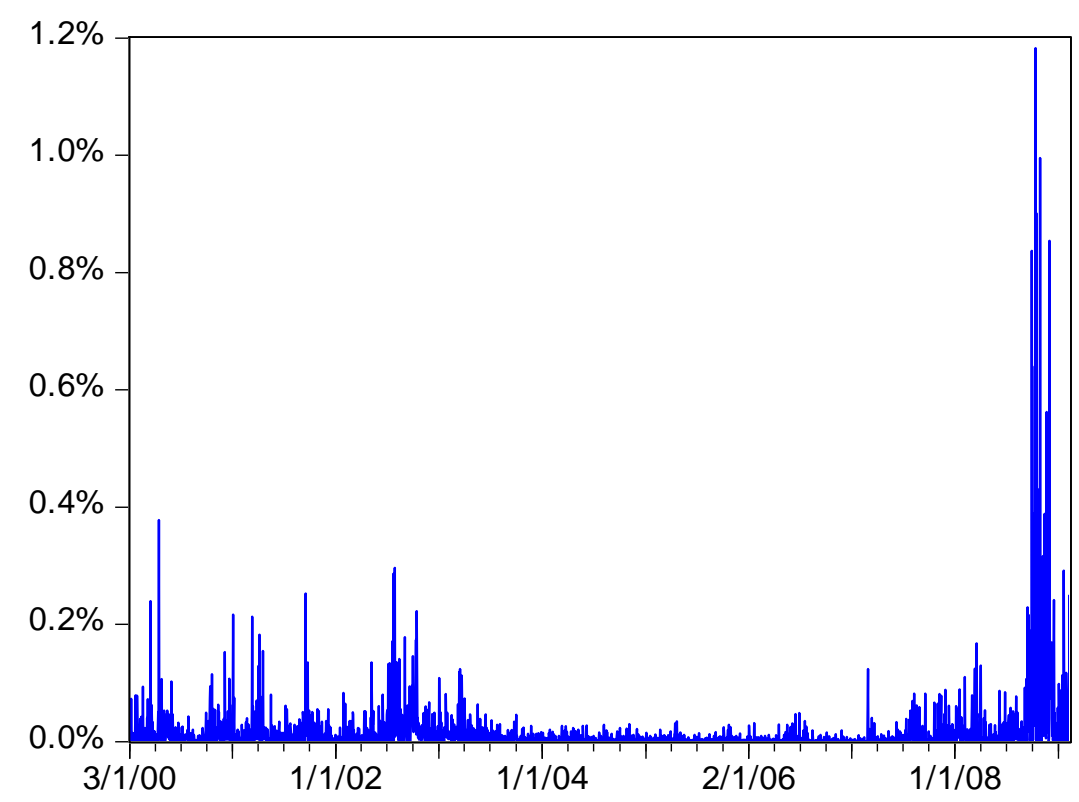


Figure 3. VaR for S\&P500 Returns

2 January 2008 - 12 February 2009

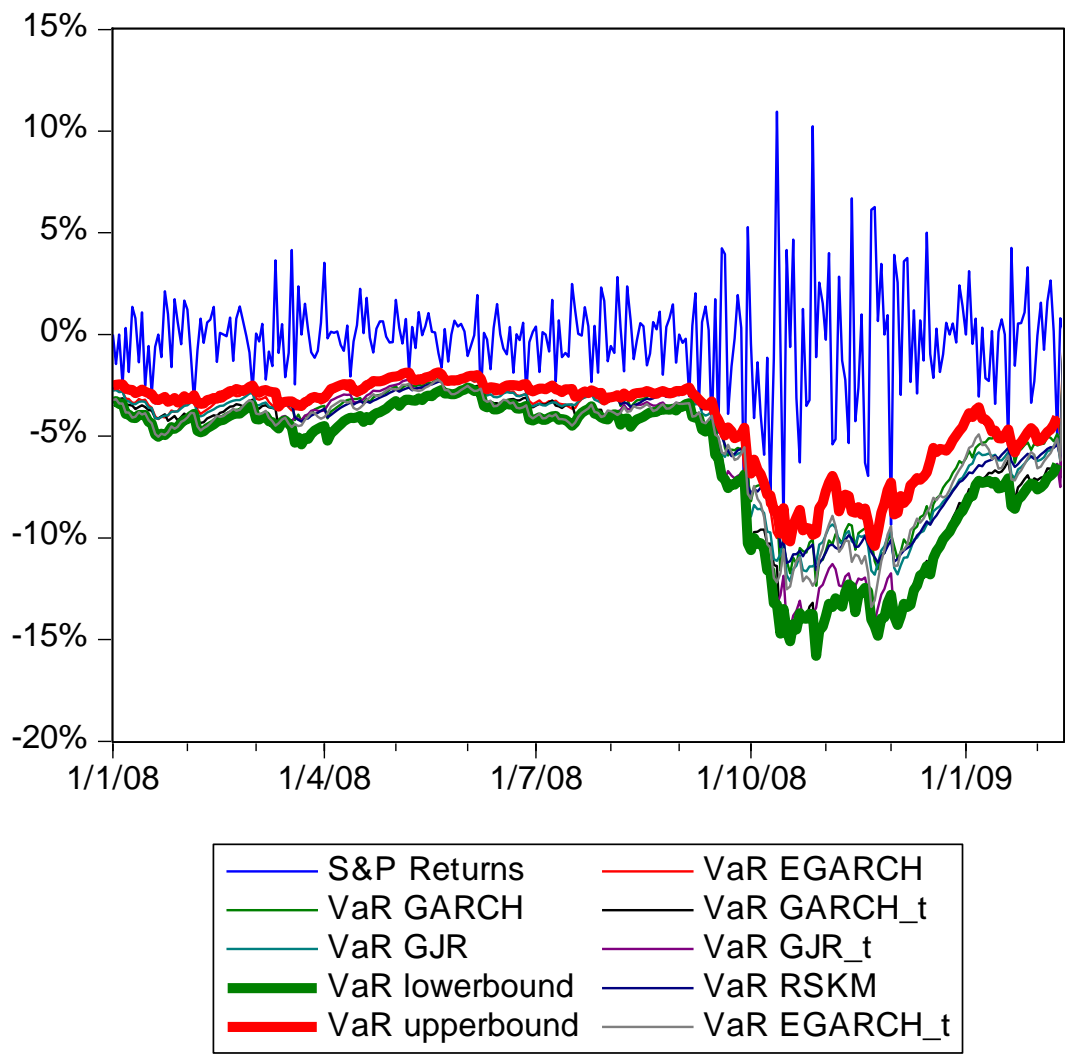

Note: The upper blue line represents daily returns for the S\&P500 index. The upper red line represents the infinum of the VaR forecasts for the different models described in Section 3. The lower green line corresponds to the supremum of the forecasts of the VaR for the same models. 
Figure 4. VaR and Mean VaR for the Previous 60 Days to Calculate Daily Capital Charges for S\&P Returns

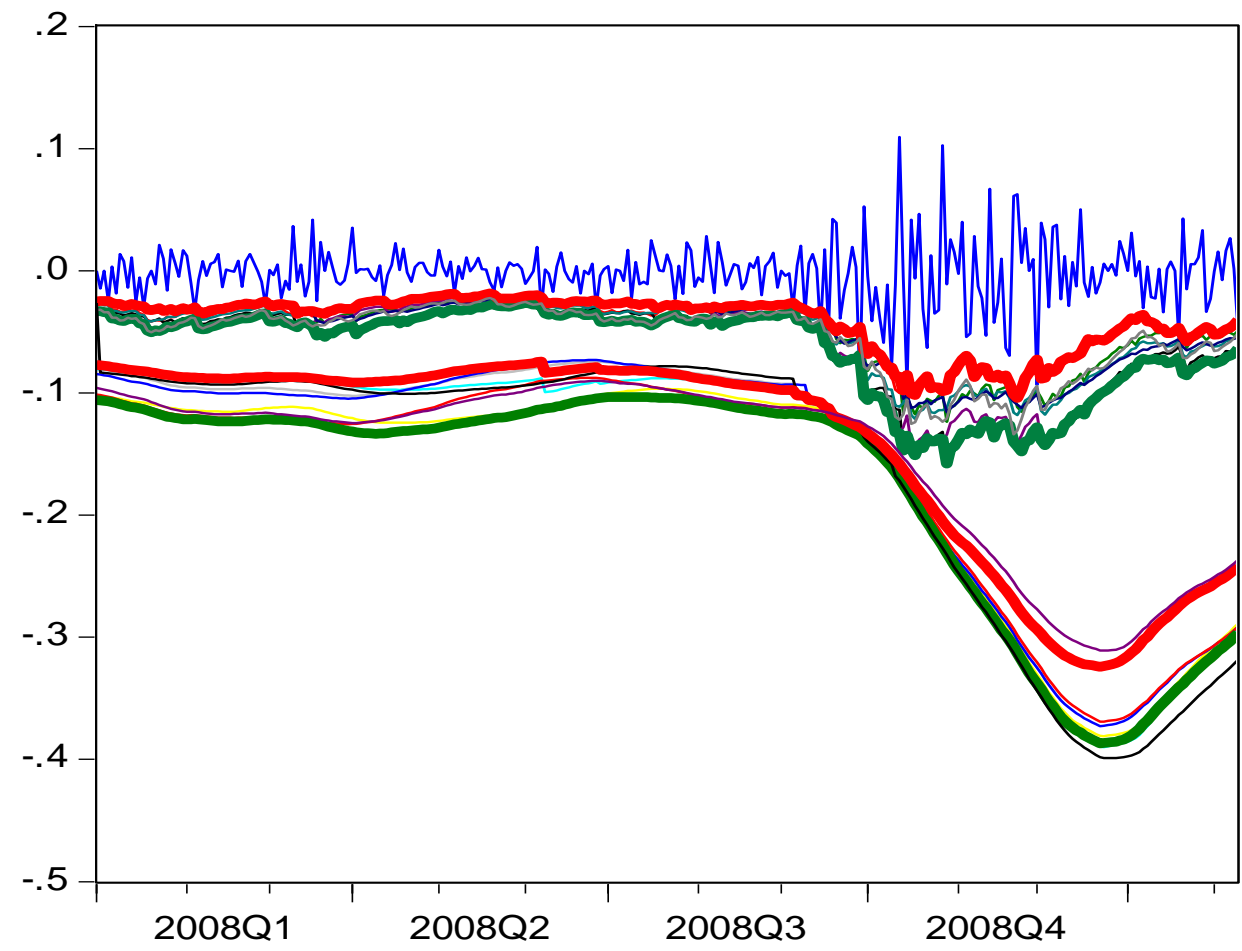

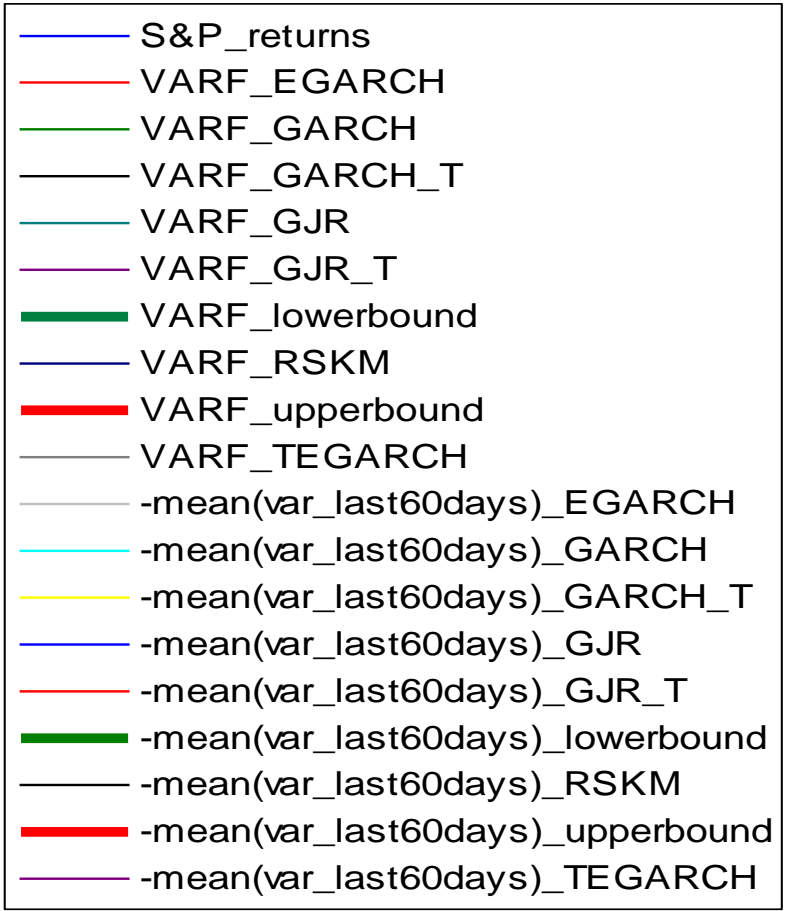


Figure 5. Number of Violations Accumulated Over 260 Days

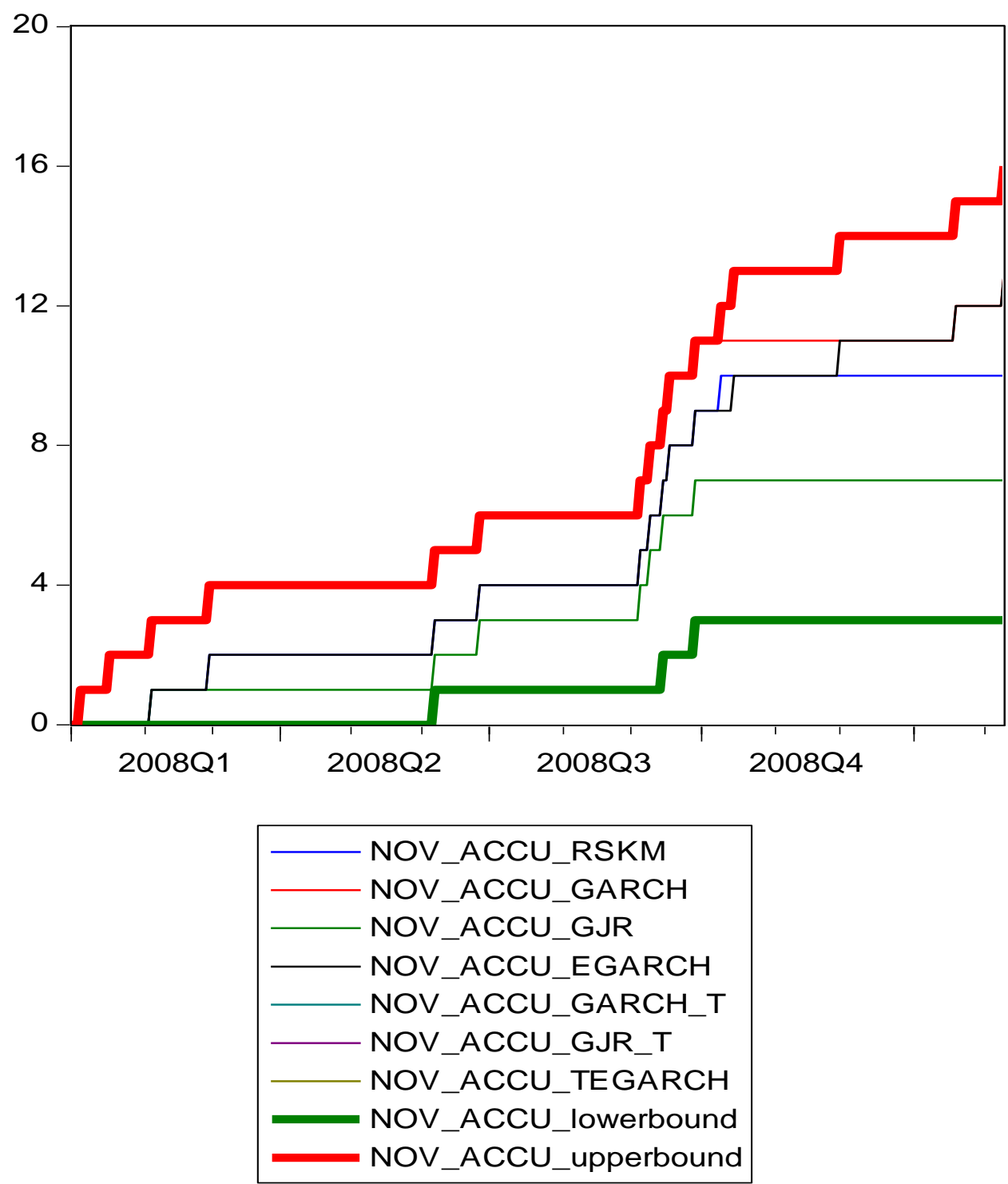


Figure 6. Duration of Minimum Daily Capital Charges for Alternative Models of Volatility

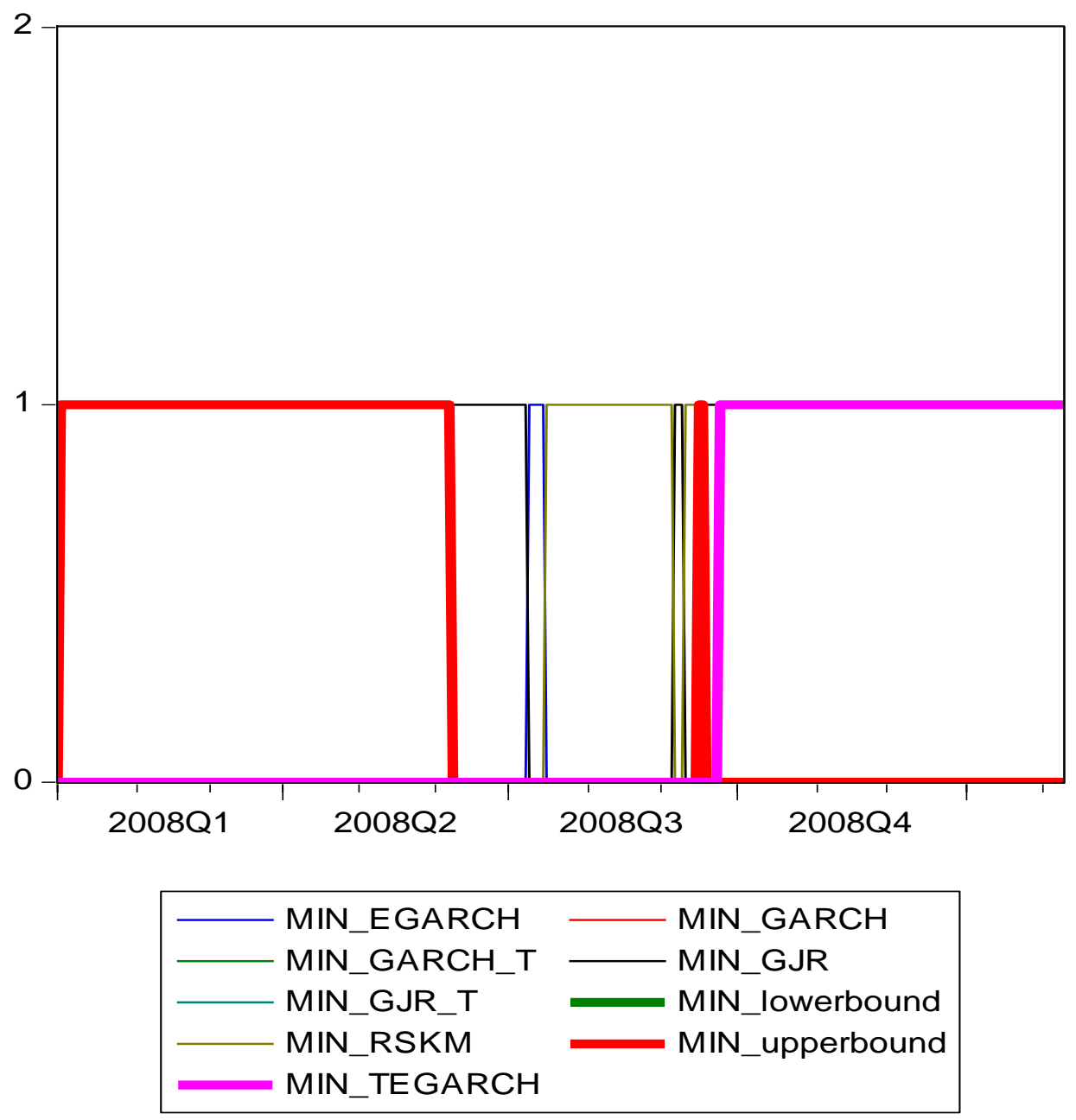

